\title{
Activity of the response regulator CiaR in mutants of Streptococcus pneumoniae R6 altered in acetyl phosphate production
}

\author{
Patrick Marx ${ }^{\dagger}$, Marina Meiers and Reinhold Brückner* \\ Department of Microbiology, University of Kaiserslautern, Kaiserslautern, Germany
}

Edited by:

Jörg Stülke,

Georg-August-Universität Göttingen,

Germany

Reviewed by:

Anne Galinier, Centre National de la

Recherche Scientifique, France

Oscar P. Kuipers, University of

Groningen, Netherlands

\section{*Correspondence:}

Reinhold Brückner, Department of

Microbiology, University of

Kaiserslautern, Paul Ehrlich Straße

23, D-67663 Kaiserslautern,

Germany

e-mail: rbrueckn@rhrk.uni-kl.de

${ }^{\dagger}$ Present address:

Patrick Marx, Department of Restorative Dentistry, Oregon Health and Science University, Portland, OR, USA
The two-component regulatory system (TCS) CiaRH of Streptococcus pneumoniae is implicated in competence, ß-lactam resistance, maintenance of cell integrity, bacteriocin production, host colonization, and virulence. Depending on the growth conditions, $\mathrm{CiaR}$ can be highly active in the absence of its cognate kinase $\mathrm{CiaH}$, although phosphorylation of $\mathrm{CiaR}$ is required for DNA binding and gene regulation. To test the possibility that acetyl phosphate (AcP) could be the alternative phosphodonor, genes involved in pyruvate metabolism were disrupted to alter cellular levels of acetyl phosphate. Inactivating the genes of pyruvate oxidase SpxB, phosphotransacetylase Pta, and acetate kinase AckA, resulted in very low AcP levels and in strongly reduced $\mathrm{CiaR}$-mediated gene expression in $\mathrm{CiaH}$-deficient strains. Therefore, alternative phosphorylation of $\mathrm{CiaR}$ appears to proceed via AcP. The AcP effect on $\mathrm{CiaR}$ is not detected in strains with $\mathrm{CiaH}$. Attempts to obtain elevated AcP by preventing its degradation by acetate kinase AckA, were not successful in $\mathrm{CiaH}$-deficient strains with a functional SpxB, the most important enzyme for AcP production in S. pneumoniae. The ciaH-spxB-ackA mutant producing intermediate amounts of AcP could be constructed and showed a promoter activation, which was much higher than expected. Since activation was dependent on AcP, it can apparently be used more efficiently for CiaR phosphorylation in the absence of AckA. Therefore, high AcP levels in the absence of $\mathrm{CiaH}$ and AckA may cause extreme overexpression of the CiaR regulon leading to synthetic lethality. AckA is also involved in a regulatory response, which is mediated by $\mathrm{CiaH}$. Addition of acetate to the growth medium switch $\mathrm{CiaH}$ from kinase to phosphatase. This switch is lost in the absence of AckA indicating metabolism of acetate is required, which starts with the production of AcP by AckA. Therefore, AckA plays a special regulatory role in the control of the CiaRH TCS.

Keywords: Streptococcus pneumoniae, two-component regulatory system CiaRH, acetyl phosphate, alternative phosphorylation, pyruvate oxidase, acetate kinase

\section{INTRODUCTION}

The two-component regulatory system (TCS) Competence Induction and Altered cefotaxime susceptibility (CiaRH) of the human pathogen Streptococcus pneumoniae is a pleiotropic regulatory device, which is involved in controlling a variety of physiological processes such as genetic competence (Sebert et al., 2005; Cassone et al., 2012), maintenance of cell integrity (Dagkessamanskaia et al., 2004; Mascher et al., 2006a), B-lactam resistance (Guenzi et al., 1994; Müller et al., 2011), bacteriocin production (Dawid et al., 2009; Kochan and Dawid, 2013), and virulence (Throup et al., 2000; Sebert et al., 2002; Ibrahim et al., 2004). CiaR belonging to the $\mathrm{OmpR}$ family of response regulators (Martínez-Hackert and Stock, 1997) and the periplasmic-sensing EnvZ-PhoQ-type (Mascher et al., 2006b) histidine kinase CiaH constitute a prototypical TCS. The response regulator CiaR controls directly 16 promoters, 15 positively and one negatively (Halfmann et al., 2007b; Denapaite et al., 2012). These promoters drive transcription of 29 genes, among them five genes specifying small non-coding RNAs (csRNAs, cia-controlled small RNAs) (Halfmann et al., 2007b). The csRNAs in turn are implicated in autolysis (Halfmann et al., 2007b), competence (Tsui et al., 2010; Schnorpfeil et al., 2013), ß-lactam resistance (Schnorpfeil et al., 2013), and virulence (Mann et al., 2012). In addition, a gene product of another member of the CiaR regulon, the serine protease $\mathrm{HtrA}$, participates in regulating most of the above mentioned phenotypes (Ibrahim et al., 2004; Cassone et al., 2012; Kochan and Dawid, 2013).

TCSs with transcription regulators as output domains typically turn gene expression on and off in response to the presence of certain stimuli (Gao and Stock, 2009; Krell et al., 2010). CiaRH however, was found to be highly active under a variety of laboratory growth conditions (Halfmann et al., 2011), but also in animal models analyzing colonization and virulence (Throup et al., 2000; Marra et al., 2002; Sebert et al., 2002; Ibrahim et al., 2004). Moreover, the system is active in various S. pneumoniae clinical isolates (Sebert et al., 2002; Lanie et al., 2007; Kumar 
et al., 2010; Tsui et al., 2010), not only in strain R6 used in this study.

Even in the absence of $\mathrm{CiaH}$, CiaR-dependent promoters are still active and their strength may even be higher than with a functional $\mathrm{CiaH}$ under certain growth conditions (Halfmann et al., 2011). On the other hand, purified CiaR did not bind to promoter fragments unless acetyl phosphate $(\mathrm{AcP})$ was added prior to the gel shift assay (Halfmann et al., 2011). A mutant form of CiaR containing an alanine instead of aspartic acid at position 51 was no longer able to activate gene expression and did not bind efficiently to promoter fragments even in the presence of AcP (Halfmann et al., 2011). Therefore, in vitro and in vivo evidence strongly suggests that the phosphorylated form of CiaR is active in DNA binding and transcriptional regulation. Nevertheless, high CiaR-dependent promoter activity is detected in the absence of $\mathrm{CiaH}$ indicating that CiaR must be able to obtain its phosphate from other sources.

Two ways are conceivable how CiaR could be phosphorylated in the absence of cognate $\mathrm{CiaH}$ kinase: Phosphorylation by another histidine kinase by cross-talk (Laub and Goulian, 2007), or cross-phosphorylation by small molecular weight highenergy donors such as AcP (Lukat et al., 1992; Wanner, 1992; Wolfe, 2010). Since in vitro CiaR DNA binding activity could be stimulated by AcP, CiaR may indeed be phosphorylated by this molecule in vivo.

Synthesis of AcP in S. pneumoniae depends on three enzymes, pyruvate oxidase $S p x B$, phosphotransacetylase Pta, and acetate kinase AckA (Spellerberg et al., 1996; Pericone et al., 2003; Ramos-Montanez et al., 2010; Carvalho et al., 2013). SpxB uses oxygen and inorganic phosphate to produce AcP and $\mathrm{H}_{2} \mathrm{O}_{2}$ directly from pyruvate. AcP production by $\mathrm{Pta}$ proceeds via acetyl-coenzyme A, which is produced by pyruvate-formate lyase (Yesilkaya et al., 2009). Finally, AckA converts AcP to acetate, which is excreted, and generates ATP. The enzyme is also able to catalyze the reverse reaction but the equilibrium is far toward ATP formation.

In the present study, we examined the hypothesis that AcP could be the phosphoryl donor for CiaR by creating mutants in the $s p x B$, pta, and ackA AcP biosynthesis genes and subsequent measurements of CiaR-mediated gene expression in the presence or absence of $\mathrm{CiaH}$. The results of these experiments provide strong evidence that $\mathrm{AcP}$ is important for CiaR phosphorylation in the absence of CiaH. They also reveal a special role of AckA in this regulation.

\section{MATERIALS AND METHODS \\ BACTERIAL STRAINS, PLASMIDS, GROWTH CONDITIONS, AND TRANSFORMATION}

The $S$. pneumoniae strains used in this study are derivatives of S. pneumoniae R6 (Ottolenghi and Hotchkiss, 1962) and are listed in Table 1. S. pneumoniae was grown at $37^{\circ} \mathrm{C}$ in static cultures without aeration in C-medium (Lacks and Hotchkiss, 1960) supplemented with $0.1 \%$ yeast extract $(\mathrm{C}+\mathrm{Y})$ or brain-heart infusion (BHI). BHI was purchased from Becton Dickinson, France. The cultures for all experiments had a volume of $10 \mathrm{ml}$ and were kept in glass tubes with a diameter of $1.4 \mathrm{~mm}$. Therefore, S. pneumoniae was grown under semi-aerobic conditions, identical to
Table 1 | S. pneumoniae strains used in this study.

\begin{tabular}{|c|c|c|}
\hline Strain $^{a}$ & Characteristics & $\begin{array}{l}\text { Sources or } \\
\text { references }\end{array}$ \\
\hline R6 & Wild type & $\begin{array}{l}\text { Ottolenghi and } \\
\text { Hotchkiss, } 1962\end{array}$ \\
\hline $\mathrm{RCH}$ & ciaH::aad9 & $\begin{array}{l}\text { Halfmann et al., } \\
2011\end{array}$ \\
\hline RKL95 & spxB::ermB & This work \\
\hline RKL399 & spxB::ermB, pta::cat & This work \\
\hline RKL369 & $\begin{array}{l}\text { spxB::ermB, pta::cat, } \\
\text { ackA::aphIII }\end{array}$ & This work \\
\hline RKL394 & spxB::ermB, ackA::aphIII & This work \\
\hline RKL380 & pta::cat & This work \\
\hline RKL416 & pta::cat, ackA::aphIII & This work \\
\hline RKL379 & ackA::aphIII & This work \\
\hline RKL400 & ciaH::aad9, spxB::ermB & This work \\
\hline RKL410 & $\begin{array}{l}\text { ciaH::aad9, spxB::ermB, } \\
\text { pta::cat }\end{array}$ & This work \\
\hline RKL373 & $\begin{array}{l}\text { ciaH::aad9, spxB::ermB, } \\
\text { pta::cat, ackA::aphIII }\end{array}$ & This work \\
\hline RKL401 & $\begin{array}{l}\text { ciaH::aad9, spxB::ermB, } \\
\text { ackA::aphIII }\end{array}$ & This work \\
\hline RKL385 & ciaH::aad9, pta::cat & This work \\
\hline RKL168 & $\mathrm{ciaH} 306, \mathrm{rps} L 41^{\mathrm{b}}$ & Müller et al., 2011 \\
\hline RKL162 & ciaH202, rpsL41 & Müller et al., 2011 \\
\hline RKL163 & ciaH305, rpsL41 & Müller et al., 2011 \\
\hline RKL164 & $\mathrm{ciaH208,rpsL41}$ & Müller et al., 2011 \\
\hline RKL165 & $\mathrm{ciaH} 408, \mathrm{rpsL41}$ & Müller et al., 2011 \\
\hline RKL243 & ciaH232, rpsL41 & Müller et al., 2011 \\
\hline RKL245 & ciaH556, rpsL41 & Müller et al., 2011 \\
\hline RKL246 & ciaH1057, rpsL41 & Müller et al., 2011 \\
\hline RKL244 & $\mathrm{ciaH}_{T p V T}, r p s L 41$ & Müller et al., 2011 \\
\hline
\end{tabular}

a All strains are $R 6$ derivatives.

b Strains contain rpsL41 (strepR) because ciaH alleles were introduced by the Janus counter-selection procedure (Sung et al., 2001).

our previous experiments. For the acetate experiments, $\mathrm{C}+\mathrm{Y}-$ medium and BHI-medium have been modified. The standard $\mathrm{C}+\mathrm{Y}$-medium contains $12.5 \mathrm{mM}$ sodium acetate (Lacks and Hotchkiss, 1960). Modified C+Y medium contained no sodium acetate, $25 \mathrm{mM}$ or $50 \mathrm{mM}$. Sodium acetate was added from a $3 \mathrm{M}$ stock solution, which had been adjusted to $\mathrm{pH} 7.8$, the $\mathrm{pH}$ of $\mathrm{C}+\mathrm{Y}$ medium. $\mathrm{BHI}$ was treated similarly, except that a $3 \mathrm{M}$ sodium acetate stock solution of $\mathrm{pH} 7.4$ was used according to the $\mathrm{pH}$ of this medium. Growth of $S$. pneumoniae was monitored by measuring optical density of $600 \mathrm{~nm}\left(\mathrm{OD}_{600}\right)$. S. pneumoniae and its derivatives were grown at $37^{\circ} \mathrm{C}$ on plates containing D-blood agar (Alloing et al., 1996). Strains with inactivated ackA were kept in an air proof candle jar containing 5\% oxygen and 10\% carbon dioxide.

The promoter probe plasmids with $E$. coli lac $Z$ as a reporter gene pPP2 containing $h t r A$, spr0931, and $c c n A$ promoters, respectively, were described previously (Halfmann et al., 2007b). The

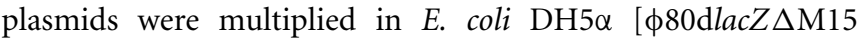
$\triangle($ lacZYA-argF) recA1 endA1 hsdR17 supE44 thi-1 gyrA96 phoA relA1] and subsequently transferred to $S$. pneumoniae strains as 
described (Halfmann et al., 2007b). Natural competent cells of S. pneumoniae were only used for the wild type R6 and the ciaH mutant RCH. The other mutant strains described in this study were transformed by the addition of CSP as described (Schnorpfeil et al., 2013), since their competence development has not been thoroughly studied. E. coli strains were grown in LB medium and transformed according to Hanahan (1983).

\section{GENE INACTIVATIONS}

The oligonucleotides used for the gene inactivations are listed in Table 2. The construction of the ciaH mutant (ciaH::aad9) has been described previously (Halfmann et al., 2011). The $s p \times B$ inactivation construct was obtained in strain S. pneumoniae D39 and its construction has been described elsewhere (Bättig and Mühlemann, 2008). The $s p x B$ gene inactivated by an erythromycin resistance gene $(s p x B:: \mathrm{erm} B)$ was amplified by primer pair spxB_fwd2, spxB_rev2 and transferred to $S$. pneumoniae R6 and its derivatives by selection on $0.5 \mu \mathrm{g} / \mu \mathrm{l}$ erythromycin. Integration was confirmed by PCR. The $s p x B$ mutant of R6 was designated RKL95 (Table 1).

To construct the pta mutant, a direct PCR cloning approach has been performed to replace nucleotides 9 to 366 of the pta coding region by the chloramphenicol resistance cassette cat. The pta coding region consists of $974 \mathrm{bp}$ and is followed immediately downstream by two IS-elements (Hoskins et al., 2001). To allow specific homologous recombination, the $3^{\prime}$-part of pta was kept. The cat gene fragment was generated by primer pair cat1, cat2 using plasmid puc18-VegM-CAT2 as template (Halfmann et al., 2007b). The upstream fragment of pta was amplified by primers ptaf1, ptar1, the downstream fragment containing the $3^{\prime}$-end of pta by primers ptaf2, ptar2. Each of the primers incorporate recognition sequences for the restriction enzymes SphI and SpeI. The amplicons were ligated subsequent to their cleavage.

Table 2 | Oligonucleotides used in this study.

\begin{tabular}{ll}
\hline Primer $^{\text {a }}$ & Sequence \\
\hline spxB_fwd2 & CGGTTCAGGTTCATACGAACGCTC \\
spxB_rev2 & CAACTGGGTTACTTTGTCAAGG \\
cat1 & GCGACTAGTTTGGACTCCTGTTGATAGATCC \\
cat2 & GGCGCATGCACAAAAAATGGACTGAACAAGTCAG \\
ptaf1 & CGCAGATGAACATGTCAAGG \\
ptar1 & GCGACTAGTCTTCCATGAGTTTTCTCCTTTAAG \\
ptaf2 & GCGGCATGCGGAGCGATTCACTCAACAGC \\
ptar2 & GGGATTTATCGTTTTACGGAC \\
ptaf3 & GGAGACGGGCTAACAGTTTC \\
ackAf2B & GCGGGATCCGAAAAGAGGAAGGAATAATAAATGG \\
ackAr2B & GCGGCATGCATTCTCAGGCACCAAGCCC \\
ackAf1 & TCTGGATGGTGAAACTGAGC \\
ackAr1B & GCGGGATCCTAACTGATACCCCTTTTAAGC \\
ackAf3B & GCGGCATGCAGTGAAACTAAAAAATATTCAATAC \\
ackAr3 & CCTGGATATTGTTCTCGAAGC \\
ackAf4 & GTGGAGCAGCAAGCAATCAAG \\
ackAr4 & TGTGCCTGTACTACGGCCTCG \\
\hline
\end{tabular}

a Recognition sites for restriction enzymes are underlined.
The ligation was re-amplified by primer pair ptaf1 and ptar2 and $S$. pneumoniae R6 transformants were selected on $3 \mu \mathrm{g} / \mathrm{ml}$ chloramphenicol to obtain strain RKL380 (pta::cat). Integration was confirmed by PCR and sequencing. Subsequently, DNA of strain RKL380 was used as template to amplify the pta::cat deletion construct with primers ptaf3 and ptar2. The amplicon was then used to move the pta deletion to different $S$. pneumoniae strains.

The ackA mutant has been constructed by replacement of the entire gene coding region with the kanamycin resistance gene aphIII (Halfmann et al., 2007b). The aphIII fragment was generated with primers ackAf2B and ackAr2B. The upstream fragment of ackA was amplified with ackAf1 and ackAr1B while the downstream fragment was amplified with primers ackAf3B and ackAr3. Each of the primers contained recognition sequences for the restriction enzymes SphI and BamHI. The amplicons were ligated subsequently to their cleavage. The entire ligation was amplified using primer pair ackAf1, ackA3r. Since problems have been reported inactivating ackA in S. pneumoniae D39 (RamosMontanez et al., 2010), this fragment was transferred first to the $s p x B$ mutant strain RKL95. Selection occurred on $100 \mu \mathrm{g} / \mathrm{ml}$ kanamycin containing blood agar plates incubated in an atmosphere with reduced oxygen $(5 \%)$ and $10 \% \mathrm{CO}_{2}$. Integration was confirmed by PCR and sequencing. Chromosomal DNA of this strain was then used to amplify the ackA::aphIII fragment to transform S. pneumoniae R6 to yield strain RKL379 and the other ackA deletion strains (Table $\mathbf{1}$ ).

Inactivation of $a c k A$ was generally performed as the latest step in strain constructions. In the presence of $c i a R H$, no problems were encountered during ack $A$ inactivation. Since genetic instability of ackA mutants was described for D39, the predecessor of R6, the genes found to be mutated in this study, $s p x B$ and $\operatorname{spxR}$ (Ramos-Montanez et al., 2010), were sequenced in several colonies of our ackA mutant strains. No alterations were detected. In the ciaH::aad9 mutant strain however, ack $A$ inactivation could not be achieved in the presence of a functional SpxB. The transformation efficiency with the ackA::aphIII fragment dropped in RCH (ciaH::aad9) or in RKL385 (ciaH::aad9, pta::cat, Table 1) by about four orders of magnitude compared to the corresponding strains with ciaRH (R6, RKL80, Table 1) or strains with inactivated $s p x B$ (RKL400, RKL410, Table 1). Since the strains with intact $s p \times B$ that could not be obtained efficiently produced large amounts of $\mathrm{H}_{2} \mathrm{O}_{2}$, katalase was added to the agar. However, transformation efficiency did not improve. The bacteria recovered in these transformations were subsequently found to have suppressor mutations in $s p x R$, but also in $c i a R$.

Mutations in ciaR were intriguing, since it suggested that an intact ciaR is detrimental in this genetic constellation. And indeed, a ciaR mutant could be efficiently transformed with the ackA::aphIII fragment. Sequencing $\operatorname{spxB}$ in a couple of transformants revealed no mutations. Thus, inactivation of $c i a H$ and $a c k A$ causes synthetic lethality, which can be suppressed by mutation of $\operatorname{sp} x B$, but also by ciaR inactivation.

Since the non-coding csRNAs and the protease HtrA were implicated in regulating various processes in S. pneumoniae (Sebert et al., 2002; Dawid et al., 2009; Schnorpfeil et al., 2013), inactivation of these genes were tested for suppression of the lethal phenotype. Deletion of the csRNA genes had no effect, 
but $h \operatorname{tr} A$ inactivation resulted in about 200 -fold more transformants. Deletion of the csRNA genes and $h t r A$ together further improved transformation tenfold. However, these transformants also acquired suppressor mutations in $s p x B$ and $c i a R$.

\section{DETERMINATION OF AcP AMOUNTS}

Determination of cellular levels of AcP was carried out according to described methods (Prüss and Wolfe, 1994; Pericone et al., 2003). All steps have been performed on ice or at $4^{\circ} \mathrm{C}$, respectively. Ten $\mathrm{ml}$ cultures of the desired strains have been grown to mid-exponential phase $\left(\mathrm{OD}_{600} 0.4\right)$ and subsequently centrifuged at $9000 \mathrm{rpm}$ for $10 \mathrm{~min}$ at $4^{\circ} \mathrm{C}$. Cell pellets were resuspended in $1 \mathrm{ml}$ ice cold luciferase buffer ( $100 \mathrm{mM}$ Tris, $4 \mathrm{mM}$ EDTA, $\mathrm{pH}$ 7.6) and transferred into $1.5 \mathrm{ml}$ tubes. The cells were lysed for $2 \mathrm{~min}$ at $95^{\circ} \mathrm{C}$. Within that time, no degradation of AcP was observed in tests using purified AcP (Sigma Aldrich). The cells were quickly cooled on ice, kept for $10 \mathrm{~min}$ and then centrifuged at $10,000 \mathrm{rpm}$ for $2 \mathrm{~min}$ at $4^{\circ} \mathrm{C}$. The supernatant was transferred to a $2 \mathrm{ml}$ tube and mixed with $50 \mathrm{mg} / \mathrm{ml}$ powdered activated charcoal (Sigma Aldrich) to remove small compounds like ADP and ATP. After incubation on ice for $15 \mathrm{~min}$, the samples have been filtered $(0.22 \mu \mathrm{m}$ pore-size $)$ to remove the charcoal. The remaining AcP in the samples was enzymatically converted into ATP by acetate kinase. Samples of $100 \mu l$ were mixed with the following compounds in the indicated final concentration: $20 \mathrm{mM}$ $\mathrm{MgCl}_{2}, 30 \mathrm{mM}$ ADP (Sigma Aldrich), $0.5 \mathrm{U} / \mu \mathrm{l}$ acetate kinase from B. stearothermophilus (Sigma Aldrich). Samples containing acetate kinase have been prepared as duplicates and one sample was prepared without acetate kinase as negative control and a control for ATP removal as well. The reaction mixtures were incubated at $30^{\circ} \mathrm{C}$ for $4 \mathrm{~h}$. The generated ATP was determined by measuring luminescence using the ATP Bioluminescence Assay Kit CLS II (Roche) following the manufacturers' instructions. Luciferase Reagent was added to the acetate kinase reaction mixtures at the ratio of 1 . Samples were incubated at room temperature for $2 \mathrm{~min}$ and ATP was determined in a BioOrbit 1253 luminometer. Data obtained from samples with acetate kinase were took as means and subtracted from data obtained from samples without acetate kinase. ATP amounts were determined by comparison with standard curves. Standard curves were generated using known AcP amounts in concentrations between 0.2 and $50 \mu \mathrm{M}$, which were converted to ATP as described above. Protein content of the samples was determined as described (Halfmann et al., 2007a) to relate AcP levels to protein.

\section{DETERMINATION OF B-GALACTOSIDASE ACTIVITY}

To assess the activity of CiaR, strains harboring CiaR-dependent promoter- $ß$-galactosidase gene (lac Z) fusions in the genome (Halfmann et al., 2007b) were assayed for B-galactosidase activity as described (Halfmann et al., 2007a). Units are expressed in nmol nitrophenol released per min and $\mathrm{mg}$ of protein.

\section{RESULTS \\ ACETYL PHOSPHATE LEVELS IN S. PNEUMONIAE R6 AND MUTANTS WITH ALTERED PYRUVATE METABOLISM}

Since the enzymes pyruvate oxidase SpxB, phosphotransacetylase Pta, and acetate kinase AckA are the key determinants for
AcP production in S. pneumoniae (Figure 1), inactivation of their genes should substantially alter AcP levels. Therefore, the respective genes were inactivated by resistance cassettes alone or in combination as described in Materials and Methods. To start with this genetic analysis the wild type strain R6 was used carrying an intact ciaRH system. The mutants were grown in $\mathrm{C}+\mathrm{Y}$ medium, the medium supporting high levels of CiaR activity in the absence CiaH (Halfmann et al., 2011), and AcP was measured as described in Materials and Methods. As shown in Figure 2A, pyruvate oxidase $\mathrm{SpxB}$ is the major enzyme involved in AcP production, a result consistent with earlier work (Pericone et al., 2003; RamosMontanez et al., 2008, 2010). The AcP level in the spxB mutant of R6 strain dropped about 20-fold, which is a larger reduction than in S. pneumoniae D39 (Pericone et al., 2003; Ramos-Montanez et al., 2008, 2010). This difference is most likely the consequence of an $s p x B$ polymorphism detected in both strains (Belanger et al., 2004; Ramos-Montanez et al., 2008). The enzyme is apparently more active in R6 (Belanger et al., 2004). Single inactivation of pta encoding phosphotransacetylase had no significant effect, but without $\mathrm{SpxB}$ and acetate kinase AckA a contribution of Pta to AcP production is detectable. Inactivation of ack $A$ in an SpxB-deficient strain increased the low level of AcP about 14fold (Figure 2A), because conversion of AcP to acetate by AckA is blocked and AcP can accumulate (Wolfe, 2005). In the spxB-pta double mutant however, ack $A$ mutation did not result in the elevation of AcP. Thus, some AcP had been produced by Pta in the absence of SpxB. Why Pta is not significantly contributing to AcP production in the presence of $\mathrm{SpxB}$ is not clear at the moment.

Growth was differently affected in the mutant strains (Table S1). The single mutants in $s p x B$ or ackA grew almost like the wild type, all other mutant strains were slower with doubling

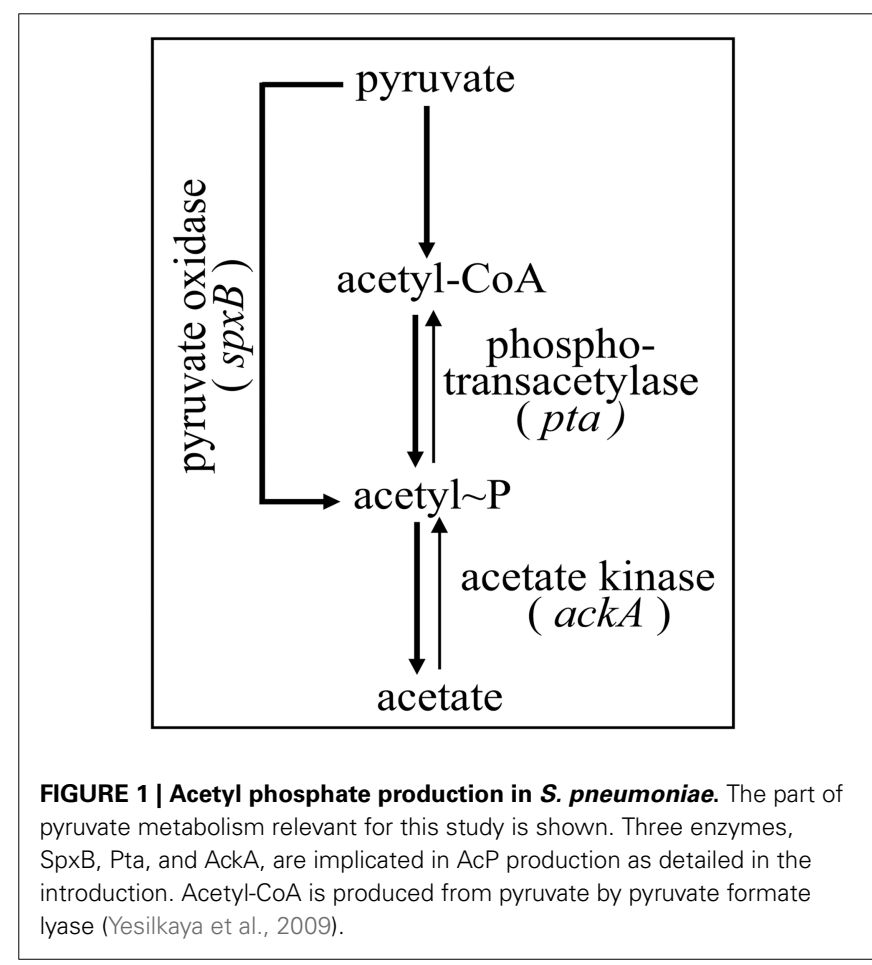



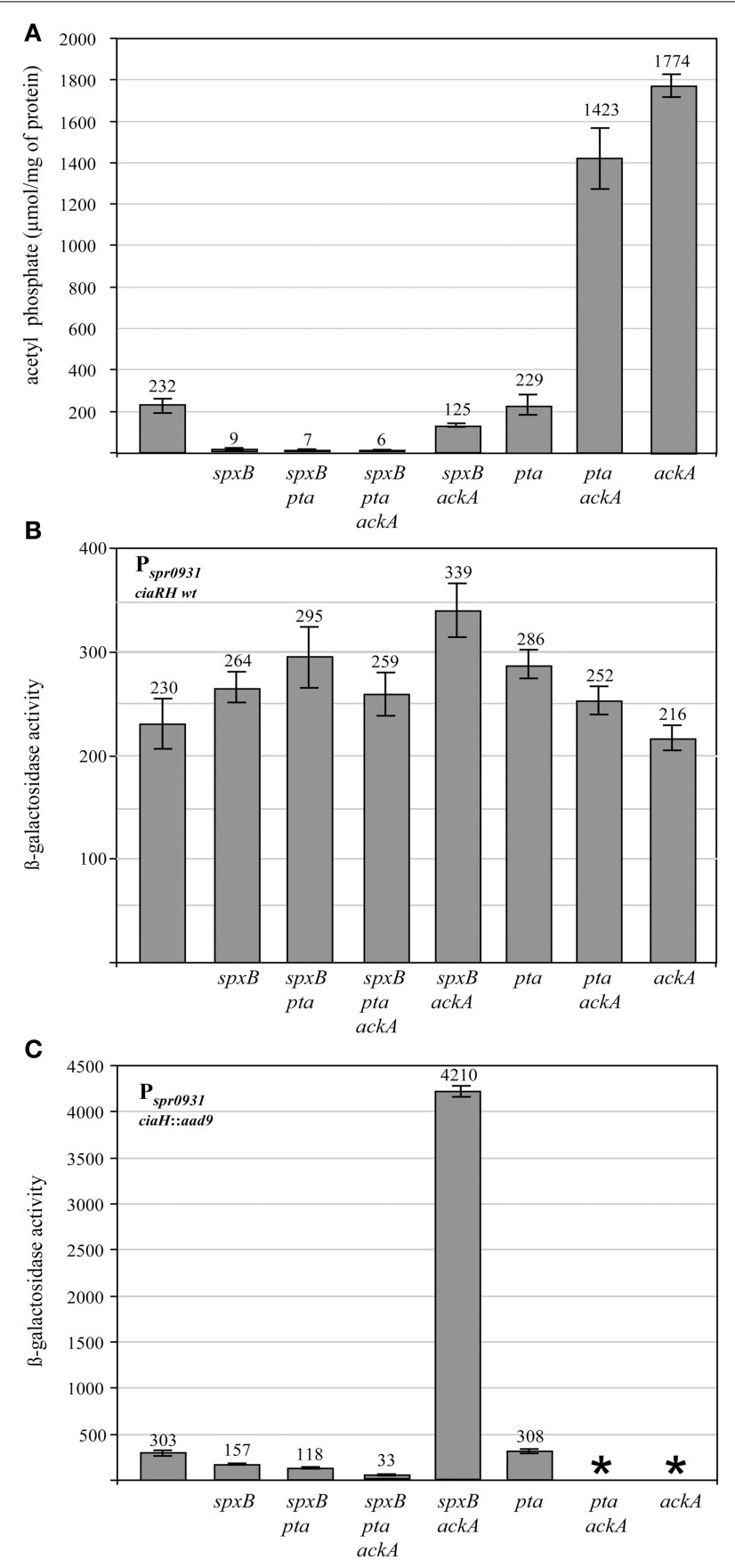

FIGURE 2 | Acetyl phosphate levels and promoter activities in pyruvate metabolism mutants of $\boldsymbol{S}$. pneumoniae R6. (A) Acetyl phosphate in pyruvate metabolism mutants. The strains were grown in $\mathrm{C}+\mathrm{Y}$ medium to mid-expontential growth phase $\left(\mathrm{OD}_{600} 0.4\right)$ and acetyl phosphate was determined from $10 \mathrm{ml}$ of the cultures. The strains used in these determinations were (from left to right): R6, RKL95 (spxB::ermB), RKL399 (spxB::ermB, pta::cat), RKL369 (spxB::ermB, pta::cat, ackA::aphlll), RKL394 (spxB::ermB, ackA::aphlll), RKL380 (pta::cat), RKL416 (pta::cat, ackA::aphIII), RKL379 (ackA::aphlII). All strains are derivatives of R6 and harbor wild type ciaRH. The inactivated genes are indicated. AcP was determined in at least two independent cultures and the values are shown along with standard deviations. (B) CiaR-dependent promoter activity in pyruvate metabolism mutants harboring ciaRH wild type. The strains were

(Continued)

\section{FIGURE 2 | Continued}

grown in $\mathrm{C}+\mathrm{Y}$ medium to an $\mathrm{OD}_{600}$ of 0.4 and $\beta$-galactosidase activity was determined. The strains were (from left to right): R6, RKL95 (spxB::ermB), RKL399 (spxB::ermB, pta::cat), RKL369 (spxB::ermB, pta::cat, ackA::aphIII), RKL394 (spxB::ermB, ackA::aphIII), RKL380 (pta::cat), RKL416 (pta::cat, ackA::aphIII), RKL379 (ackA::aphIII). All strains contained a P spr0931

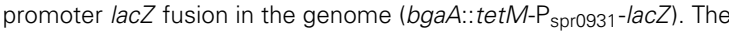
promoter of spr0931 is activated by CiaR and its activity is strictly CiaR-dependent. Two other promoters, $\mathrm{P}_{h t r A}$ and $\mathrm{P}_{c c n A}$, reacted as $\mathrm{P}_{\text {spro931 }}$ and a CiaR-independent promoter $\mathrm{P}_{\text {veg }}$ showed no change in activity. The inactivated genes are indicated. Values of at least three independent cultures are shown along with standard deviations. B-galactosidase units are expressed in nmol nitrophenol released per min and $\mathrm{mg}$ of protein.(C) CiaR-dependent promoter activity in pyruvate metabolism mutants harboring inactivated $\mathrm{ciaH}$. The strains were (from left to right): RCH (ciaH::aad9), RKL400 (ciaH::aad9, spxB::ermB), RKL410 (ciaH::aad9, spxB::ermB, pta::cat), RKL373 (ciaH::aad9, spxB::ermB, pta::cat, ackA::aphIII), RKL401 (ciaH::aad9, spxB::ermB, ackA::aphlll), RKL385 (ciaH::aad9, pta::cat). *Indicates that these strains could not be constructed. All strains had a $\mathrm{P}_{\text {spro931 }}$ promoter lacZ fusion in the genome

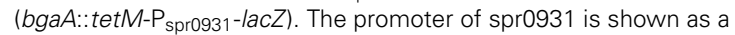
representative for $\mathrm{CiaR}$-dependent promoters. The control promoter $\mathrm{P}_{\text {veg }} \mathrm{M}$ was not affected. All strains are $\mathrm{CiaH}$-deficient. The inactivated genes are indicated. Values of at least three independent cultures are shown along with standard deviations. ß-galactosidase units are expressed in $\mathrm{nmol}$ nitrophenol released per min and $\mathrm{mg}$ of protein.

times ranging between 45 and $55 \mathrm{~min}$ compared to $37 \mathrm{~min}$ of the wild type.

The AcP determinations in this series of $S$. pneumoniae R6 pyruvate metabolism mutants largely confirmed what could be expected from the literature (Pericone et al., 2003; Wolfe, 2005; Ramos-Montanez et al., 2010). Without SpxB and Pta, AcP production is virtually absent. AcP produced by SpxB or Pta accumulates, when ackA is inactivated. Consequently, R6 derivatives are available covering a wide range of AcP levels. Since the AcP synthesis mutants were constructed to analyze the connection of AcP to CiaRH-mediated gene expression, it was of interest to determine whether $\mathrm{CiaRH}$ could influence AcP levels. AcP determinations in CiaR-, and CiaH-deficient as well as in CiaRH hyperactive strains (Müller et al., 2011) did not reveal an influence (Figure $\mathrm{S} 1$ ).

\section{CiaR-MEDIATED GENE EXPRESSION IN AcP SYNTHESIS MUTANTS IN THE PRESENCE OF CiaH}

During the initial characterization of the $\mathrm{CiaR}$ regulon (Halfmann et al., 2007b), all CiaR-controlled promoters were cloned into an integrative reporter plasmid (Halfmann et al., 2007a). These constructs are well-suited to analyze CiaRdependent gene expression (Halfmann et al., 2007b; Müller et al., 2011). Therefore, three of these promoter fusions, $P_{\text {spr0931 }}, P_{h t r A}$, and $\mathrm{P}_{c c n A}$, were introduced into the mutant strains described above as representatives of the CiaR regulon. They were chosen because their activity is strongly dependent on $\mathrm{CiaR}$ and there is no evidence that they are controlled by other regulators (Halfmann et al., 2007b). Measuring the promoter activities in $\mathrm{C}+\mathrm{Y}$ medium revealed only subtle changes in an almost identical range for all promoters (data not shown). As a representative example, $\mathrm{P}_{\text {spro931 }}$ mediated $\mathrm{B}$-galactosidase expression determined in the middle of exponential growth $\left(\mathrm{OD}_{600} 0.4\right)$ is 
shown in Figure 2B. In general, promoter activities are slightly higher in almost all mutant strains. The ackA-pta mutant showed the strongest activation with an increase of 1.5-fold. Similar results were obtained measuring earlier $\left(\mathrm{OD}_{600} \quad 0.2\right)$ or later $\left(\mathrm{OD}_{600} 0.8\right)$. Considering that AcP levels vary more than 100 -fold (Figure 2A), one can conclude that CiaR-dependent promoters are not influenced by AcP under these conditions. The strains used in this series of experiments carried wild type ciaRH. Therefore, $\mathrm{CiaH}$ will predominantly control the phosphorylation status of CiaR and thereby promoter activities.

\section{CiaR-MEDIATED GENE EXPRESSION IN AcP SYNTHESIS MUTANTS IN THE ABSENCE OF CiaH}

Since cross-phosphorylation or cross-talk in TCSs is quite often only detected in the absence of cognate histidine kinases (Laub and Goulian, 2007), it was of interest to determine promoter activities in the AcP synthesis mutants without $\mathrm{CiaH}$. And indeed, drastic changes were detected in the ciaH mutant strains (Figure 2C), quite in contrast to the strains carrying ciaRH wild type (Figure $2 B$ ). Inactivation of $s p x B$ resulted in a twofold reduction of $\mathrm{P}_{\text {spr0931 }}$ activity. The other CiaR-dependent promoters reacted accordingly (data not shown). While $p t a$ inactivation in the $s p x B$ mutant resulted in a further 2.5-fold reduction, promoter activity dropped about tenfold in the $s p x B$-pta-ackA triple mutant. Therefore, inactivation of the genes of pyruvate metabolism, which resulted in the reduction of AcP (Figure 2A) clearly diminished CiaR-dependent transcription. Accordingly, no change was observed in the pta mutant (Figure 2C), which had wild type AcP levels (Figure 2A).

A surprising result, however, has been obtained in the $s p x B$ ack $A$ mutant strain (Figure 2C). Although AcP is about twofold reduced compared to the wild type (Figure 2A), transcription from CiaR-dependent promoters is tremendously increased. $\mathrm{P}_{\text {spr0931 }}$ activity rose about 14-fold (Figure 2C). In addition, inactivation of $a c k A$ in strains with intact $s p x B$, which are characterized by a high amount of AcP (Figure 2A) could not be achieved. Disruption of the same genes was possible in strains with a functional CiaH, but also in the absence of CiaR (see Materials and Methods). Considering the very strong $\mathrm{P}_{\mathrm{spr} 0931}$ activation in the $s p x B$-ackA-ciaH mutant strain, it appears that the inability to introduce mutations in ackA to strains with a functional $\mathrm{SpxB}$ in the absence of $\mathrm{CiaH}$ is caused by extreme activation of the CiaR regulon. We have shown previously that strong activation of the CiaR regulon by mutations in ciaH could impair growth (Müller et al., 2011). It is therefore conceivable, that higher activation of CiaR-mediated transcription in the AckA-deficient strains could lead to lethality.

The results of these experiments clearly demonstrate a strong influence of the pyruvate metabolism on CiaR-mediated gene expression, provided the cognate kinase $\mathrm{CiaH}$ was absent. Promoter activation was strongly reduced in strains producing low amounts of AcP, which would be consistent with AcP as the alternative route of phosphorylation for CiaR in the absence of $\mathrm{CiaH}$. The experiments also show that there is no strict correlation between the AcP level and promoter activation. Especially in the absence of AckA in the $s p x B$ mutant background, CiaR is disproportionally activated.

\section{THE INFLUENCE OF ACETATE IN THE GROWTH MEDIUM ON CiaR-MEDIATED GENE EXPRESSION}

In contrast to the growth of $S$. pneumoniae in $\mathrm{C}+\mathrm{Y}$ medium, which supports high levels of CiaR-dependent transcription in the absence of $\mathrm{CiaH}$, the same promoters are only weakly active in brain heart infusion (BHI) medium (Halfmann et al., 2011). Measuring AcP in BHI medium revealed an almost threefold reduction $(81 \pm 9 \mu \mathrm{mol} / \mathrm{mg}$ of protein) compared to $\mathrm{C}+\mathrm{Y}$ medium (Figure 1), again indicating that AcP levels modulate $\mathrm{CiaR}$ activity in the absence of $\mathrm{CiaH}$. This medium was therefore well-suited to test if exogenously added acetate could enhance $\mathrm{CiaR}$ activation in the absence of $\mathrm{CiaH}$. As shown in Figure 3,

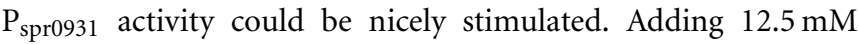
sodium acetate, the concentration found in $\mathrm{C}+\mathrm{Y}$ medium, activation was moderate (1.5 fold), but twofold ( $25 \mathrm{mM}$ ) or fourfold $(50 \mathrm{mM})$ more sodium acetate enhanced the promoter activity seven- and thirtyfold, respectively (Figure 3). The addition of potassium acetate had the same effect, while sodium chloride did not change $\mathrm{P}_{\text {spr0931 }}$ activity (Figure S2). In conclusion, the observed effect appears to be specific for acetate. Repeating these experiments in $\mathrm{C}+\mathrm{Y}$ medium with altered acetate concentration yielded in principle the same results, but the change in expression was less pronounced (Figure S3). Unexpectedly, measuring AcP in BHI supplemented with acetate, did not reveal a significant increase, not even with the highest concentration.

Another surprising result was obtained measuring promoter activities in the wild type ciaRH strain as control. In this strain, addition of acetate to $50 \mathrm{mM}$ reduced the promoter activity about twofold compared to the values obtained without acetate supplementation (Figure 3). In comparison with the activity measured without $\mathrm{CiaH}$ however, promoter strength is tenfold reduced. This comparison strongly suggests that $\mathrm{CiaH}$ acts as a phosphatase when acetate concentrations are high in the growth medium. Modifying acetate concentrations in $\mathrm{C}+\mathrm{Y}$ medium altered CiaR-mediated expression similarly, but again less pronounced (Figure S4), indicating that CiaR is dephosphorylated under these conditions. These results are in accordance with the previous notion that $\mathrm{CiaH}$ acts as a phosphatase in standard $\mathrm{C}+\mathrm{Y}$ medium (Halfmann et al., 2011).

The effect of acetate on $\mathrm{CiaH}$ activity could be caused directly by binding to $\mathrm{CiaH}$, or indirectly, which would require metabolism of acetate. In the latter case, regulation should depend on AckA, since internalized acetate must be phosphorylated for further metabolism. Therefore, the ackA mutant strain was tested in BHI medium and in BHI with $50 \mathrm{mM}$ sodium acetate. The acetate effect was virtually gone upon ack $A$ inactivation (Figure S5). Therefore, the change of CiaH activity is not caused by acetate itself. Metabolism is required to produce a signal that may then be detected by $\mathrm{CiaH}$.

\section{RESPONSE TO ACETATE IN THE GROWTH MEDIUM BY VARIANTS OF CiaH}

Since $\mathrm{CiaH}$ appeared to respond to a signal produced by metabolism of acetate, it was of interest to test variants of $\mathrm{CiaH}$, which have been analyzed in some detail previously (Müller et al., 2011). The majority of these ciaH mutants (Table 1) have been obtained in screens aimed at isolating ß-lactam resistant mutants 


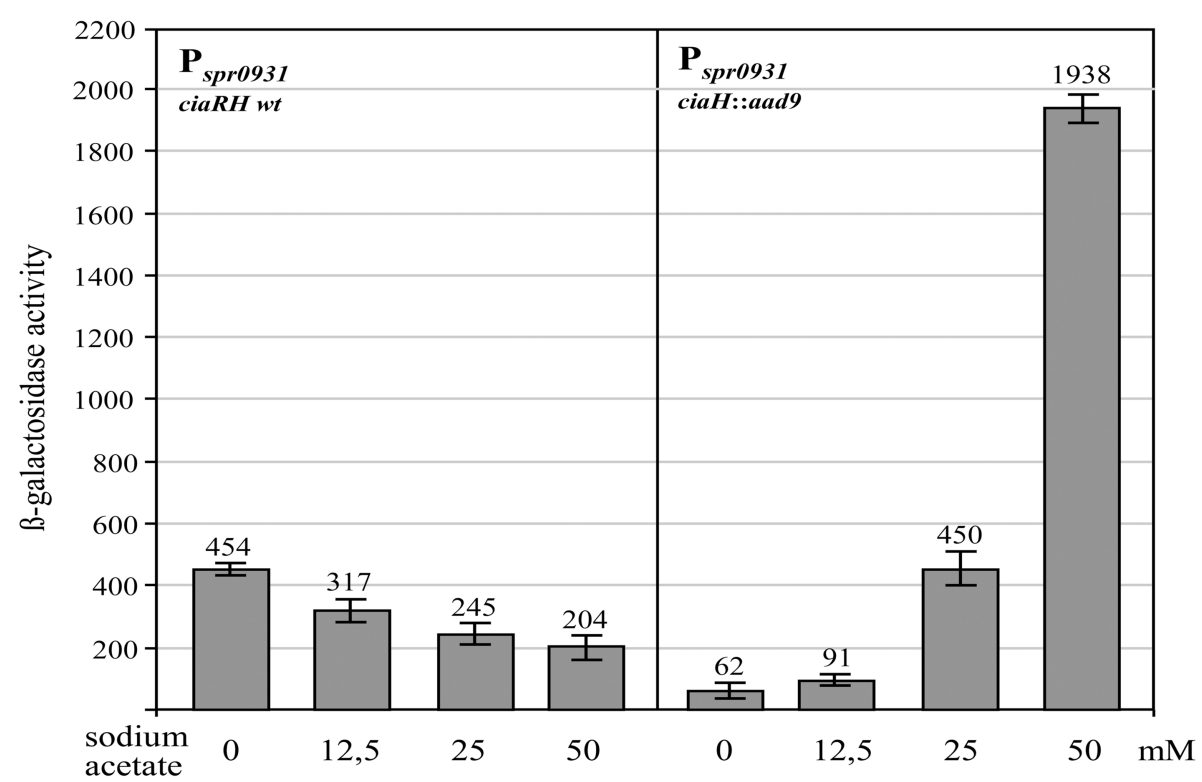

FIGURE 3 | Effect of acetate supplementation of the growth medium on CiaR-dependent promoter activity. The strains were grown in $\mathrm{BHI}$ medium containing the indicated concentrations of sodium acetate to an $\mathrm{OD}_{600}$ of 0.4 and $ß$-galactosidase was measured. The comparison of the promoter activities of the R6 wild type harboring $\mathrm{ciaRH}$ (four measurements from the left) with those found in the CiaH-deficient mutant $\mathrm{RCH}$ (ciaH::aad9) is shown. All

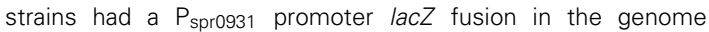

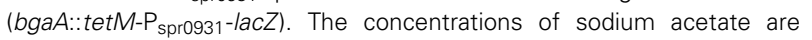
indicated. Values of at least three independent cultures are shown along with standard deviations. B-galactosidase units are expressed in $\mathrm{nmol}$ nitrophenol released per min and $\mathrm{mg}$ of protein. of S. pneumoniae R6 (Guenzi et al., 1994; Zähner et al., 2002), but a few were also detected in ciaH genes of clinical isolates (Müller et al., 2011). Common to all these ciaH alleles, with one exception, is their ability to enhance CiaR-mediated gene expression to higher levels compared to the wild type R6. In some cases, hyperactivation of CiaR is the consequence of the mutations in $\mathrm{ciaH}$ (Müller et al., 2011).

Promoter activities were measured in these strains in $\mathrm{BHI}$ and BHI with $50 \mathrm{mM}$ sodium acetate. As shown in Figure 4, the response to acetate is quite variable. In the mutants obtained in the laboratory, reduction of promoter activities was not observed. In three of these strains, promoter strength was even slightly higher. Quite in contrast, three CiaH variants from clinical isolates reacted more strongly than the wild type (Figure 4), with repression rates of fourfold (ciaH556, ciaH1057) or even higher (ciaH232). The latter allele is the only one which did not enhance CiaR-mediated gene expression (Müller et al., 2011). One clinical variant ( $c i a H T p V T$ ) behaved like the wild type. Interestingly, three CiaH variants, CiaH305, CiaH408, and CiaH232, reacting differently, have alterations in the extracytoplasmic part of the protein. Binding of an unknown factor may have been affected by these mutations. In any case, the differential response of several $\mathrm{CiaH}$ variants to acetate in the medium is a strong indication that the effect is specifically mediated by $\mathrm{CiaH}$.

\section{DISCUSSION}

Genetic inactivation of genes involved in the production of AcP (Figure 1) resulted in S. pneumoniae strains producing drastically different amounts of AcP (Figure 2A). While the double mutant in $s p x B$ and pta produced very little or perhaps no AcP, inactivation of ackA alone or in combination with $p t a$, raised AcP to very high levels (Figure 2A). Under latter conditions, concomitant inactivation of $\mathrm{ciaH}$ was not possible. Measuring CiaR-dependent promoters in an $s p x B$-ackA background, a strain producing intermediate AcP amounts (Figure $2 \mathrm{~A}$ ), revealed a very strong increase in promoter activity (Figure $\mathbf{2 C}$ ). It appears therefore, that the inability to construct ackA-ciaH and ackA-pta-ciaH mutants is caused by overactivation of CiaR and consequently overexpression of the CiaR regulon. And indeed, the ackA mutation could be combined with an inactivated ciaR gene (ciaR::aad9) and could be constructed in ciaRH wild type. In this strain, $\mathrm{CiaH}$ is able to reduce CiaR-dependent gene expression back to wild type levels (Figure 2B). Interestingly, in a study to determine the role of $\mathrm{AcP}$ in the regulation of the orphan response regulator DegU in Listeria monocytogenes, ackA inactivation could not be achieved unless pta was also inactivated (Gueriri et al., 2008).

The strains in which ack $A$ could not be inactivated together with $c i a H$ produce high amounts of $\mathrm{H}_{2} \mathrm{O}_{2}$ because of the activity of SpxB (Spellerberg et al., 1996; Pericone et al., 2003; RamosMontanez et al., 2008). $\mathrm{H}_{2} \mathrm{O}_{2}$ production alone cannot account for the lethality, since CiaRH does not affect $s p x B$ expression (own unpublished observations). The detrimental concerted action of $\mathrm{H}_{2} \mathrm{O}_{2}$ and one or more overexpressed members of the CiaR regulon remains a possibility. The stress protease HtrA appears to be one of these factors.

In contrast to the problems with ack $A$ inactivation detailed above and also contrary to the strong activation of CiaRdependent promoters in the spxB-ackA mutant strain, ackA 


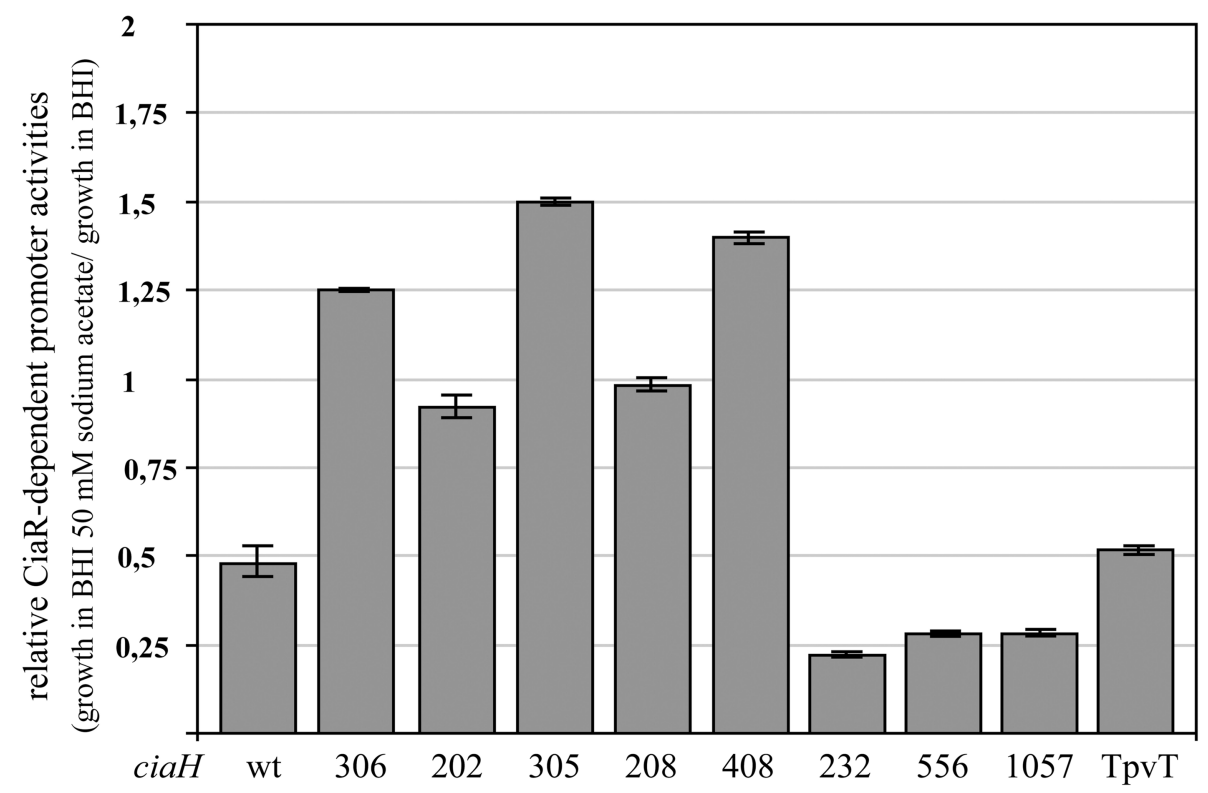

FIGURE 4 | Change of CiaR-dependent promoter activities upon acetate supplementation in strains harboring varriants of $\mathbf{c i a H}$. The strains were grown in $\mathrm{BHI}$ medium containing $50 \mathrm{mM}$ of sodium acetate or $\mathrm{BHI}$ without the addition of acetate to an $\mathrm{OD}_{600}$ of 0.4 and $ß$-galactosidase was measured. Activities of two promoters, $P_{\text {htrA }}$ and $P_{\text {spro931, were determined }}$ under both growth conditions and the relative expression rate was calculated by dividing the value of the acetate supplemented culture by the value of the untreated sample. All strains contained promoter fusions in the genome

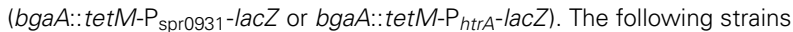
were used (from left to right): R6, RKL168 (ciaH306), RKL162 (ciaH202), RKL163 (ciaH305), RKL164 ( $\mathrm{ciaH} 208)$, RKL165 (ciaH408), RKL243 (ciaH232), RKL245 (ciaH556), RKL246 (ciaH1057), RKL244 (ciaHTpVT). The ciaH allele numbers are indicated. Values of at least two independent cultures of each promoter harboring strain are shown along with standard deviations. mutation in a $s p x B$-pta mutant background was readily achieved and promoted only low levels of CiaR-mediated gene expression (Figure 2C). Reducing AcP levels by sequential inactivation of $s p x B$, pta, and ackA concomitantly lowered CiaR-dependent promoter activities tenfold in the absence of $\mathrm{CiaH}$ (Figure 2C). Therefore, CiaR clearly responds to AcP levels. Since phosphorylation is needed for CiaR activity and CiaR binding to promoter fragments in vitro is stimulated by AcP (Halfmann et al., 2011), combined evidence suggests that AcP may indeed serve as alternative source of phosphorylation for CiaR. One can always argue that an unknown histidine kinase phosphorylates CiaR by cross-talk in response to varying levels of AcP, but we consider this possibility less likely than AcP-dependent phosphorylation.

Although reduced AcP levels resulted in lower activity of CiaR, the response is not always proportional. The ciaH-spxB-ackA mutant produced about half of the AcP found in the wild type (Figure 2A), but promoter activities raised more than tenfold. In addition, ackA mutants with functional SpxB are not viable (see above). On the other hand, ackA inactivation did not increase promoter activities in strains producing spurious amounts of AcP ( $s p x B$-pta; Figure 2C). Thus, the effect of AckA on CiaR activity is dependent on AcP. It appears, that CiaR can use AcP as phosphodonor more efficiently in the absence of AckA. At the current stage of knowledge, it is impossible to offer conclusive explanations. An attractive hypothesis, however, would be a direct interaction between AckA and CiaR, which according to our data should lead to reduced phosphorylation of CiaR by AcP. Enzymes with additional roles in other processes are rather widespread also in bacteria (Wang et al., 2013). Prominent examples of these socalled moon-lighting proteins in bacteria are glycolytic enzymes serving also as receptors for various molecules on the bacterial surface (Wang et al., 2013). Furthermore, a number of enzymes play regulatory roles in complex physiological processes and were proposed to be called trigger enzymes (Commichau and Stülke, 2008). According to our hypothesis, AckA could be such a trigger enzyme. Interestingly, a number of bacteria possess two ackA genes, but the analysis of their physiological roles has just started (Chan et al., 2014; Puri et al., 2014). Intriguingly, gene duplication events are quite often associated with trigger enzymes leading to speciation of variants acting then as enzymes or as regulators (Commichau and Stülke, 2008).

The experiments to enhance CiaR-mediated gene regulation by the addition of acetate to the BHI medium constitutes another example, in which AcP levels do not correlate with promoter activities. Although the CiaR-dependent promoters were stimulated about 30 -fold by the addition of $50 \mathrm{mM}$ sodium acetate (Figure 3), AcP levels were not significantly elevated under these conditions. Promoter activation was completely lost (Figure S5), when a ciaR mutant (ciaR152) was tested, which expressed a non-phosphorylatable D51A variant of CiaR (Halfmann et al., 2011). Therefore, phosphorylation of CiaR is required to see the acetate effect. Without higher amounts of acetate in BHI medium, CiaR is apparently not able to use the AcP efficiently that is present in BHI grown cells. Since almost the same effects of acetate addition were observed in $\mathrm{C}+\mathrm{Y}$ medium (Figure S3), 
this regulatory event appears to be general and not specific for BHI, where it is detected best.

To take up again our hypothesis of CiaR-AckA interaction, these results may indicate that this interaction could be regulated according to the activity of AckA or to the availability of the substrates AcP and acetate. It is clearly too early to speculate further on this type of regulation, especially because extremely little is known in $S$. pneumoniae about ackA expression or regulation of AckA activity, which has been shown in other organisms to be subject to allosteric control (Puri et al., 2014). In Borrelia burgdorferi, an orphan response regulator Rrp2 was also strongly stimulated by acetate in the growth medium, but AcP levels have not been determined (Xu et al., 2010).

A further effect of acetate addition to BHI medium was detected in the wild type (Figure 3). In the presence of $\mathrm{CiaH}$, the promoter stimulating effect observed in the absence of $\mathrm{CiaH}$ is converted to a reduction (Figure 3). It appears that the phosphatase activity of $\mathrm{CiaH}$ is stimulated under these conditions. Without added acetate CiaH acts a kinase, but with 25 or $50 \mathrm{mM}$ acetate as a phosphatase. Since this regulation is also dependent on AckA (Figure S5), it is very unlikely that acetate itself serves as the signal for CiaH. Rather, acetate should be metabolized to produce a signal that is sensed by $\mathrm{CiaH}$. Since $\mathrm{CiaH}$ is lacking a recognizable intracellular sensing domain, this unknown stimulus should be located outside the cell. And indeed, three of the CiaH mutants (CiaH305, 408, 232) showing a different response compared to the wild type have amino acid substitutions in the extracytoplasmic sensing domain.

What could be the signal CiaH is responding to? Considering that $\mathrm{CiaRH}$ is implicated in B-lactam resistance and maintenance of cell integrity (Guenzi et al., 1994; Mascher et al., 2006a) and that CiaR responds to AcP levels, a tempting candidate would be acetylated peptidoglycan (Vollmer, 2008). In S. pneumoniae, acetylation of peptidoglycan could be quite variable since mainly $\mathrm{N}$-acetylglucosamine and to a lesser extent $\mathrm{N}$-acetylmuramic acid can be deacetylated (Vollmer and Tomasz, 2000) and $\mathrm{N}$-acetylmuramic acid is additionally O-acetylated (Crisostomo et al., 2006). Both processes are not essential for peptidoglycan synthesis and could be regulated and variable.

In a simple scenario, high levels of AcP, which can phosphorylate CiaR and raise its activity to high levels, would lead to more peptidoglycan acetylation, which could turn on $\mathrm{CiaH}$ phosphatase activity reducing $\mathrm{CiaR}$ activation virtually back to wild type levels. How higher peptidoglycan acetylation could be achieved by $\mathrm{AcP}$ is an open question. However, recent evidence clearly demonstrates that the role of AcP in acetylation at least of proteins is much more prominent than anticipated (Verdin and Ott, 2013; Weinert et al., 2013; Kuhn et al., 2014). It remains a possibility that AcP may also be a determinant in the acetylation of other compounds.

Acetylation can also be involved in the additional control of TCSs (Barak et al., 2006; Lima et al., 2011, 2012; Hu et al., 2013; Kuhn et al., 2014) and as mentioned above, AcP can serve as an acetyl donor in protein acetylation. Therefore, protein acetylation should also be altered in the S. pneumoniae AcP synthesis mutants described in this study. Could then acetylation explain the CiaRrelated fluctuations in gene expression phenotypes rather than phosphorylation? The response of CiaR is clearly dependent on phosphorylation and $\mathrm{CiaH}$ is in complete control, but the strength of the change in activity may be additionally modified by protein acetylation. The genetic arguments for a special role of AckA in the process of CiaR activation remain the same. In the absence of AckA, CiaR is disproportionally active. Assuming this overactivation is caused by phosphorylation and acetylation, the underlying mechanisms would be more complicated than our proposed model.

The $S$. pneumoniae strain used throughout this study is the laboratory strain R6 derived from S. pneumoniae D39, which was used to identify DNA as the genetic material (Avery et al., 1944). Considering the great variety between strains of bacterial species, it is always the question whether findings in one strain also apply to others. In microarray studies of AcP production mutants in D39 it was reported that expression of several members of the CiaR regulon is reduced in a triple $s p x B$-pta-ackA harboring ciaRH (Ramos-Montanez et al., 2010). In our study, expression went down only in the absence of ciaH. Strain D39 and R6 show about 80 differences, among them $\operatorname{spxB}$ (Lanie et al., 2007). But even considering the higher activity of SpxB in R6 (Belanger et al., 2004; Ramos-Montanez et al., 2008), we cannot offer an explanation for the observed difference. Curiously, two D39 variants that were kept separately for some time differed in their CiaRH-mediated gene regulation (Lanie et al., 2007). Therefore, it appears that strain-specific variations in regulatory circuits may be encountered quite frequently.

$\mathrm{CiaRH}$ and at least one major player in the regulatory processes analyzed in this study, $\mathrm{SpxB}$, can be regarded as virulence factors (Spellerberg et al., 1996; Ibrahim et al., 2004). The human pathogen S. pneumoniae faces varying concentrations of oxygen and different carbohydrates in its natural host, which will inevitably change AcP levels. Since CiaRH appears to have evolved to maintain high levels of regulon expression under a variety of conditions, it would be reasonable to safeguard high expression by AcP-mediated CiaR phosphorylation, in case no appropriate signal to stimulate $\mathrm{CiaH}$ kinase activity is available. Since all $S$. pneumoniae genomes sequenced so far harbor ciaRH and $s p \times B$, this scenario may indeed be important for survival of S. pneumoniae in its natural host.

\section{ACKNOWLEDGMENTS}

We thank Regine Hakenbeck for her continuous interest and support. We also thank A. J. Wolfe for helpful discussions during the preparation of the manuscript. We acknowledge the contributions of Ulrike Günzler, Jennifer Grün, Lisa König, and especially Alexander Halfmann to the project.

\section{SUPPLEMENTARY MATERIAL}

The Supplementary Material for this article can be found online at: http://www.frontiersin.org/journal/10.3389/fmicb.2014. 00772/abstract

\section{REFERENCES}

Alloing, G., Granadel, C., Morrison, D. A., and Claverys, J. P. (1996). Competence pheromone, oligopeptide permease, and induction of competence in Streptococcus pneumoniae. Mol. Microbiol. 21, 471-478. doi: 10.1111/j.13652958.1996.tb02556.x 
Avery, O. T., Macleod, C. M., and Mccarty, M. (1944). Studies on the chemical nature of the substance inducing transformation of pneumococcal types: induction of transformation by a desoxyribonucleic acid fraction isolated from pneumococcus type III. J. Exp. Med. 79, 137-158. doi: 10.1084/jem.79.2.137

Barak, R., Yan, J., Shainskaya, A., and Eisenbach, M. (2006). The chemotaxis response regulator $\mathrm{CheY}$ can catalyze its own acetylation. J. Mol. Biol. 359, 251-265. doi: 10.1016/j.jmb.2006.03.033

Bättig, P., and Mühlemann, K. (2008). Influence of the $s p x B$ gene on competence in Streptococcus pneumoniae. J. Bacteriol. 190, 1184-1189. doi: 10.1128/JB. 01517-07

Belanger, A. E., Clague, M. J., Glass, J. I., and Leblanc, D. J. (2004). Pyruvate oxidase is a determinant of Avery's rough morphology. J. Bacteriol. 186, 8164-8171. doi: 10.1128/JB.186.24.8164-8171.2004

Carvalho, S. M., Farshchi Andisi, V., Gradstedt, H., Neef, J., Kuipers, O. P., Neves, A. R., et al. (2013). Pyruvate oxidase influences the sugar utilization pattern and capsule production in Streptococcus pneumoniae. PLoS ONE 8:e68277. doi: 10.1371/journal.pone.0068277

Cassone, M., Gagne, A. L., Spruce, L. A., Seeholzer, S. H., and Sebert, M. E. (2012). The HtrA Protease from Streptococcus pneumoniae digests both denatured proteins and the competence-stimulating peptide. J. Biol. Chem. 287, 38449-38459. doi: 10.1074/jbc.M112.391482

Chan, S. H., Norregaard, L., Solem, C., and Jensen, P. R. (2014). Acetate kinase isozymes confer robustness in acetate metabolism. PLoS ONE 9:e92256. doi: 10.1371/journal.pone.0092256

Commichau, F. M., and Stülke, J. (2008). Trigger enzymes: bifunctional proteins active in metabolism and in controlling gene expression. Mol. Microbiol. 67, 692-702. doi: 10.1111/j.1365-2958.2007.06071.x

Crisostomo, M. I., Vollmer, W., Kharat, A. S., Inhulsen, S., Gehre, F., Buckenmaier, S., et al. (2006). Attenuation of penicillin resistance in a peptidoglycan O-acetyl transferase mutant of Streptococcus pneumoniae. Mol. Microbiol. 61, 1497-1509. doi: 10.1111/j.1365-2958.2006.05340.x

Dagkessamanskaia, A., Moscoso, M., Henard, V., Guiral, S., Overweg, K., Reuter, M., et al. (2004). Interconnection of competence, stress and CiaR regulons in Streptococcus pneumoniae: competence triggers stationary phase autolysis of ciaR mutant cells. Mol. Microbiol. 51, 1071-1086. doi: 10.1111/j.13652958.2003.03892.x

Dawid, S., Sebert, M. E., and Weiser, J. N. (2009). Bacteriocin activity of Streptococcus pneumoniae is controlled by the serine protease HtrA via posttranscriptional regulation. J. Bacteriol. 191, 1509-1518. doi: 10.1128/JB. 01213-08

Denapaite, D., Brückner, R., Hakenbeck, R., and Vollmer, W. (2012). Biosynthesis of teichoic acids in Streptococcus pneumoniae and closely related species: lessons from genomes. Microb. Drug. Resist. 18, 344-358. doi: 10.1089/mdr.2012.0026

Gao, R., and Stock, A. M. (2009). Biological insights from structures of two-component proteins. Annu. Rev. Microbiol. 63, 133-154. doi: 10.1146/annurev.micro.091208.073214

Guenzi, E., Gasc, A. M., Sicard, M. A., and Hakenbeck, R. (1994). A two-component signal-transducing system is involved in competence and penicillin susceptibility in laboratory mutants of Streptococcus pneumoniae. Mol. Microbiol. 12, 505-515. doi: 10.1111/j.1365-2958.1994.tb01038.x

Gueriri, I., Bay, S., Dubrac, S., Cyncynatus, C., and Msadek, T. (2008). The PtaAckA pathway controlling acetyl phosphate levels and the phosphorylation state of the DegU orphan response regulator both play a role in regulating Listeria monocytogenes motility and chemotaxis. Mol. Microbiol. 70, 1342-1357. doi: 10.1111/j.1365-2958.2008.06496.x

Halfmann, A., Hakenbeck, R., and Brückner, R. (2007a). A new integrative reporter plasmid for Streptococcus pneumoniae. FEMS Microbiol. Lett. 268, 217-224. doi: 10.1111/j.1574-6968.2006.00584.x

Halfmann, A., Kovács, M., Hakenbeck, R., and Brückner, R. (2007b). Identification of the genes directly controlled by the response regulator CiaR in Streptococcus pneumoniae: five out of 15 promoters drive expression of small noncoding RNAs. Mol. Microbiol. 66, 110-126. doi: 10.1111/j.1365-2958.2007. 05900.x

Halfmann, A., Schnorpfeil, A., Müller, M., Marx, P., Günzler, U., Hakenbeck, R., et al. (2011). Activity of the two-component regulatory system CiaRH in Streptococcus pneumoniae R6. J. Mol. Microbiol. Biotechnol. 20, 96-104. doi: $10.1159 / 000324893$

Hanahan, D. (1983). Studies on transformation of Escherichia coli with plasmids. J. Mol. Biol. 166, 557-580. doi: 10.1016/S0022-2836(83)80284-8
Hoskins, J., Alborn, W. E. Jr., Arnold, J., Blaszczak, L. C., Burgett, S., Dehoff, B. S., et al. (2001). Genome of the Bacterium Streptococcus pneumoniae Strain R6. J. Bacteriol. 183, 5709-5717. doi: 10.1128/JB.183.19.5709-5717.2001

Hu, L. I., Chi, B. K., Kuhn, M. L., Filippova, E. V., Walker-Peddakotla, A. J., Basell, K., et al. (2013). Acetylation of the response regulator RcsB controls transcription from a small RNA promoter. J. Bacteriol. 195, 4174-4186. doi: 10.1128/JB.00383-13

Ibrahim, Y. M., Kerr, A. R., Mccluskey, J., and Mitchell, T. J. (2004). Control of virulence by the two-component system $\mathrm{CiaR} / \mathrm{H}$ is mediated via $\mathrm{HtrA}$, a major virulence factor of Streptococcus pneumoniae. J. Bacteriol. 186, 5258-5266. doi: 10.1128/JB.186.16.5258-5266.2004

Kochan, T. J., and Dawid, S. (2013). The HtrA protease of Streptococcus pneumoniae controls density-dependent stimulation of the bacteriocin blp locus via disruption of pheromone secretion. J. Bacteriol. 195, 1561-1572. doi: 10.1128/JB.01964-12

Krell, T., Lacal, J., Busch, A., Silva-Jimenez, H., Guazzaroni, M. E., and Ramos, J. L. (2010). Bacterial sensor kinases: diversity in the recognition of environmental signals. Annu. Rev. Microbiol. 64, 539-559. doi: 10.1146/annurev.micro.112408.134054

Kuhn, M. L., Zemaitaitis, B., Hu, L. I., Sahu, A., Sorensen, D., Minasov, G., et al. (2014). Structural, kinetic and proteomic characterization of acetyl phosphate-dependent bacterial protein acetylation. PLoS ONE 9:e94816. doi: 10.1371/journal.pone.0094816

Kumar, R., Shah, P., Swiatlo, E., Burgess, S. C., Lawrence, M. L., and Nanduri, B. (2010). Identification of novel non-coding small RNAs from Streptococcus pneumoniae TIGR4 using high-resolution genome tiling arrays. BMC Genomics 11:350. doi: 10.1186/1471-2164-11-350

Lacks, S., and Hotchkiss, R. D. (1960). A study of the genetic material determining an enzyme in Pneumococcus. Biochim. Biophys. Acta 39, 508-518. doi: 10.1016/0006-3002(60)90205-5

Lanie, J. A., Ng, W. L., Kazmierczak, K. M., Andrzejewski, T. M., Davidsen, T. M., Wayne, K. J., et al. (2007). Genome sequence of Avery's virulent serotype 2 strain D39 of Streptococcus pneumoniae and comparison with that of unencapsulated laboratory strain R6. J. Bacteriol. 189, 38-51. doi: 10.1128/JB.01148-06

Laub, M. T., and Goulian, M. (2007). Specificity in two-component signal transduction pathways. Annu. Rev. Genet. 41, 121-145. doi: 10.1146/annurev.genet.41.042007.170548

Lima, B. P., Antelmann, H., Gronau, K., Chi, B. K., Becher, D., Brinsmade, S. R., et al. (2011). Involvement of protein acetylation in glucose-induced transcription of a stress-responsive promoter. Mol. Microbiol. 81, 1190-1204. doi: 10.1111/j.1365-2958.2011.07742.x

Lima, B. P., Thanh Huyen, T. T., Basell, K., Becher, D., Antelmann, H., and Wolfe, A. J. (2012). Inhibition of acetyl phosphate-dependent transcription by an acetylatable lysine on RNA polymerase. J. Biol. Chem. 287, 32147-32160. doi: 10.1074/jbc.M112.365502

Lukat, G. S., Mccleary, W. R., Stock, A. M., and Stock, J. B. (1992). Phosphorylation of bacterial response regulator proteins by low molecular weight phosphodonors. Proc. Natl. Acad. Sci. U. S. A. 89, 718-722. doi: 10.1073/pnas. 89.2.718

Mann, B., Van Opijnen, T., Wang, J., Obert, C., Wang, Y. D., Carter, R., et al. (2012). Control of virulence by small RNAs in Streptococcus pneumoniae. PLoS Pathog. 8:e1002788. doi: 10.1371/journal.ppat.1002788

Marra, A., Asundi, J., Bartilson, M., Lawson, S., Fang, F., Christine, J., et al. (2002). Differential fluorescence induction analysis of Streptococcus pneumoniae identifies genes involved in pathogenesis. Infect. Immun. 70, 1422-1433. doi: 10.1128/IAI.70.3.1422-1433.2002

Martínez-Hackert, E., and Stock, A. M. (1997). Structural relationships in the OmpR family of winged-helix transcription factors. J. Mol. Biol. 269, 301-312. doi: 10.1006/jmbi.1997.1065

Mascher, T., Heintz, M., Zähner, D., Merai, M., and Hakenbeck, R. (2006a). The CiaRH system of Streptococcus pneumoniae prevents lysis during stress induced by treatment with cell wall inhibitors and mutations in $p b p 2 x$ involved in ß-lactam resistance. J. Bacteriol. 188, 1959-1978. doi: 10.1128/JB.188.5.19591968.2006

Mascher, T., Helmann, J. D., and Unden, G. (2006b). Stimulus perception in bacterial signal-transducing histidine kinases. Microbiol. Mol. Biol. Rev. 70, 910-938. doi: 10.1128/MMBR.00020-06

Müller, M., Marx, P., Hakenbeck, R., and Brückner, R. (2011). Effect of new alleles of the histidine kinase gene $c i a H$ on the activity of the response 
regulator CiaR in Streptococcus pneumoniae R6. Microbiology 157, 3104-3112. doi: 10.1099/mic.0.053157-0

Ottolenghi, E., and Hotchkiss, R. D. (1962). Release of genetic transforming agent from pneumococcal cultures during growth and disintegration. J. Exp. Med. 116, 491-519. doi: 10.1084/jem.116.4.491

Pericone, C. D., Park, S., Imlay, J. A., and Weiser, J. N. (2003). Factors contributing to hydrogen peroxide resistance in Streptococcus pneumoniae include pyruvate oxidase $(\mathrm{SpxB})$ and avoidance of the toxic effects of the fenton reaction. J. Bacteriol. 185, 6815-6825. doi: 10.1128/JB.185.23.6815-6825.2003

Prüss, B. M., and Wolfe, A. J. (1994). Regulation of acetyl phosphate synthesis and degradation, and the control of flagellar expression in Escherichia coli. Mol. Microbiol. 12, 973-984. doi: 10.1111/j.1365-2958.1994.tb01085.x

Puri, P., Goel, A., Bochynska, A., and Poolman, B. (2014). Regulation of acetate kinase isozymes and its importance for mixed-acid fermentation in Lactococcus lactis. J. Bacteriol. 196, 1386-1393. doi: 10.1128/JB.01277-13

Ramos-Montanez, S., Kazmierczak, K. M., Hentchel, K. L., and Winkler, M. E. (2010). Instability of ackA (Acetate Kinase) mutations and their effects on acetyl phosphate (AcP) and ATP Amounts in Streptococcus pneumoniae D39. J. Bacteriol. 192, 6390-6400. doi: 10.1128/JB.00995-10

Ramos-Montanez, S., Tsui, H. C., Wayne, K. J., Morris, J. L., Peters, L. E., Zhang, F., et al. (2008). Polymorphism and regulation of the $\operatorname{spxB}$ (pyruvate oxidase) virulence factor gene by a CBS-HotDog domain protein (SpxR) in serotype 2 Streptococcus pneumoniae. Mol. Microbiol. 67, 729-746. doi: 10.1111/j.13652958.2007.06082.x

Schnorpfeil, A., Kranz, M., Kovacs, M., Kirsch, C., Gartmann, J., Brunner, I., et al. (2013). Target evaluation of the non-coding csRNAs reveals a link of the twocomponent regulatory system CiaRH to competence control in Streptococcus pneumoniae R6. Mol. Microbiol. 89, 334-349. doi: 10.1111/mmi.12277

Sebert, M. E., Palmer, L. M., Rosenberg, M., and Weiser, J. N. (2002). Microarraybased identification of $h t r A$, a Streptococcus pneumoniae gene that is regulated by the CiaRH two-component system and contributes to nasopharyngeal colonization. Infect. Immun. 70, 4059-4067. doi: 10.1128/IAI.70.8.4059-4067.2002

Sebert, M. E., Patel, K. P., Plotnick, M., and Weiser, J. N. (2005). Pneumococcal HtrA protease mediates inhibition of competence by the CiaRH two-component signaling system. J. Bacteriol. 187, 3969-3979. doi: 10.1128/JB.187.12.3969-3979.2005

Spellerberg, B., Cundell, D. R., Sandros, J., Pearce, B. J., Idanpaan-Heikkila, I., Rosenow, C., et al. (1996). Pyruvate oxidase, as a determinant of virulence in Streptococcus pneumoniae. Mol. Microbiol. 19, 803-813. doi: 10.1046/j.13652958.1996.425954.x

Sung, C. K., Li, H., Claverys, J. P., and Morrison, D. A. (2001). An rpsL cassette, janus, for gene replacement through negative selection in Streptococcus pneumoniae. Appl. Environ. Microbiol. 67, 5190-5196. doi: 10.1128/AEM.67.11.51905196.2001

Throup, J. P., Koretke, K. K., Bryant, A. P., Ingraham, K. A., Chalker, A. F., Ge, Y., et al. (2000). A genomic analysis of two-component signal transduction in Streptococcus pneumoniae. Mol. Microbiol. 35, 566-576. doi: 10.1046/j.13652958.2000.01725.x

Tsui, H. C., Mukherjee, D., Ray, V. A., Sham, L. T., Feig, A. L., and Winkler, M. E. (2010). Identification and characterization of noncoding small RNAs in Streptococcus pneumoniae serotype 2 strain D39. J. Bacteriol. 192, 264-279. doi: 10.1128/JB.01204-09
Verdin, E., and Ott, M. (2013). Acetylphosphate: a novel link between lysine acetylation and intermediary metabolism in bacteria. Mol. Cell. 51, 132-134. doi: 10.1016/j.molcel.2013.07.006

Vollmer, W. (2008). Structural variation in the glycan strands of bacterial peptidoglycan. FEMS Microbio.l Rev. 32, 287-306. doi: 10.1111/j.15746976.2007.00088.x

Vollmer, W., and Tomasz, A. (2000). The $p g d A$ gene encodes for a peptidoglycan Nacetylglucosamine deacetylase in Streptococcus pneumoniae. J. Biol. Chem. 275, 20496-20501. doi: 10.1074/jbc.M910189199

Wang, G., Xia, Y., Cui, J., Gu, Z., Song, Y., Chen, Y. Q., et al. (2013). The roles of moonlighting proteins in bacteria. Curr. Issues Mol. Biol. 16, 15-22.

Wanner, B. L. (1992). Is cross regulation by phosphorylation of twocomponent response regulator proteins important in bacteria? J. Bacteriol. 174, 2053-2058.

Weinert, B. T., Iesmantavicius, V., Wagner, S. A., Scholz, C., Gummesson, B., Beli, P., et al. (2013). Acetyl-phosphate is a critical determinant of lysine acetylation in E. coli. Mol. Cell 51, 265-272. doi: 10.1016/j.molcel.2013.06.003

Wolfe, A. J. (2005). The acetate switch. Microbiol. Mol. Biol. Rev. 69, 12-50. doi: 10.1128/MMBR.69.1.12-50.2005

Wolfe, A. J. (2010). Physiologically relevant small phosphodonors link metabolism to signal transduction. Curr. Opin. Microbiol. 13, 204-209. doi: 10.1016/j.mib.2010.01.002

Xu, H., Caimano, M. J., Lin, T., He, M., Radolf, J. D., Norris, S. J., et al. (2010). Role of acetyl-phosphate in activation of the Rrp2-RpoN-RpoS pathway in Borrelia burgdorferi. PLoS Pathog 6:e1001104. doi: 10.1371/annotation/88293342-3534$4 \mathrm{~b} 8 \mathrm{~b}-8800-\mathrm{c} 63 \mathrm{a} 8 \mathrm{c} 86 \mathrm{bf} 6 \mathrm{~d}$

Yesilkaya, H., Spissu, F., Carvalho, S. M., Terra, V. S., Homer, K. A., Benisty, R., et al. (2009). Pyruvate formate lyase is required for pneumococcal fermentative metabolism and virulence. Infect. Immun. 77, 5418-5427. doi: 10.1128/IAI.00178-09

Zähner, D., Kaminski, K., Van Der Linden, M., Mascher, T., Merai, M., and Hakenbeck, R. (2002). The ciaR/ciaH regulatory network of Streptococcus pneumoniae. J. Mol. Microbiol. Biotechnol. 4, 211-216.

Conflict of Interest Statement: The authors declare that the research was conducted in the absence of any commercial or financial relationships that could be construed as a potential conflict of interest.

Received: 08 November 2014; accepted: 17 December 2014; published online: 15 January 2015.

Citation: Marx P, Meiers $M$ and Brückner $R$ (2015) Activity of the response regulator CiaR in mutants of Streptococcus pneumoniae R6 altered in acetyl phosphate production. Front. Microbiol. 5:772. doi: 10.3389/fmicb.2014.00772

This article was submitted to Microbial Physiology and Metabolism, a section of the journal Frontiers in Microbiology.

Copyright (C) 2015 Marx, Meiers and Brückner. This is an open-access article distributed under the terms of the Creative Commons Attribution License (CC BY). The use, distribution or reproduction in other forums is permitted, provided the original author(s) or licensor are credited and that the original publication in this journal is cited, in accordance with accepted academic practice. No use, distribution or reproduction is permitted which does not comply with these terms. 